\title{
JOGOS DA LINGUAGEM E A AUTOCOMPOSIÇÃO ADMINISTRATIVA
}

\author{
Clóvis Marinho de Barros Falcão* \\ Rafael Sousa Fonsêca ${ }^{\dagger}$
}

\section{Resumo:}

O Direito decorre e faz uso das palavras, escritas ou faladas. E percebeu-se com o passar do tempo que vários problemas como mal-entendidos e equívocos decorriam da linguagem utilizada. Assim, verificou-se que a linguagem se valia de um jogo, em que o significado da palavra variava de acordo com o seu uso. No âmbito jurídico, esse jogo de linguagem, como argumentação jurídica, é o meio essencial para que a autocomposição obtenha resultados mais justos e alcance o bem-estar comum.

Palavras-chave: Jogos de linguagem. Palavra. Significado. Autocomposição. Justiça.

\section{LANGUAGE GAMES AND ALTERNATIVE DISPUTES RESOLUTION IN ADMINISTRATIVE AREA}

\begin{abstract}
:
The law stems and makes use of words, written or spoken. And it was realized over time that various problems like misunderstandings and misconceptions stemmed the language used. Thus, it was found that language value is a game where the meaning of the word varied according to its use. In the legal context, this language game is the essential means for the alternative disputes resolution get fairer results and reach of the common welfare.
\end{abstract}

Keywords: Language games. Word. Meaning. Alternative disputes resolution. Justice.

\section{INTRODUÇÃO}

A cultura oriental, iniciada pelos gregos, trouxe a concepção do discurso como fenômeno intersubjetivo específico, quem discursa age. (FERRAZ, 1997). No uso deste discurso, foi verificada a existência de problemas de compreensão.

*Professor da Graduação e da Pós-Graduação em Direito da Universidade Federal de Sergipe. Endereço eletrônico: clovisfalcao@gmail.com

${ }^{\dagger}$ Conselheiro Substituto do Tribunal de Contas do Estado de Sergipe. Mestrando da Pós-graduação em Direito da Universidade Federal de Sergipe. Endereço eletrônico: rafaelfonseca@uol.com.br.

Rev. de Teorias da Justiça, da Decisão e da Argumentação Jurídica | e-ISSN: 2525-9644| Maranhão | v. 3 | n. 2 | p. 37 - 52 | Jul/Dez. 2017. 
A partir destes problemas (mal-entendidos e equívocos) na linguagem falada e escrita, esta passou a ter uma atenção especial de alguns pensadores até tornar-se um campo de investigação filosófica. A função da linguagem seria então fazer com que a expressão do pensamento encontrasse sentido com a realidade, sob pena de sermos incompreendidos.

Dentro deste panorama temos que o direito é expresso em palavras e, na maioria das vezes, é criado pelo uso de palavras (RAZ, 1978). Assim a busca por um modelo de fala que produza resultados mais justos na aplicação do Direito é fundamental para a promoção do bem comum de todos que estão sujeitos à correção normativa.

Então, em um cenário onde, devido à "crise na justiça", surgiu a necessidade de novas formas de composição de conflitos, formando o que Ada Pellegrini Grinover (2015) denominou de "cultura de conciliação", os denominados jogos de linguagem de Wittgenstein são mais do que necessários para a aplicação do bom direito.

De fato, os métodos consensuais de solução dos litígios vêm sendo gradativamente acolhidos pelo ordenamento jurídico pátrio, em especial a autocomposição, que consiste na finalização da controvérsia pelas próprias partes interessadas, chegando a um entendimento comum por meio de transação, renúncia ou reconhecimento do direito pertencente à outra parte.

Nesse contexto, é possível verificar essa tendência ao consensualismo também no âmbito da Administração Pública e sua atual forma de atuação gerencial, mais aberta ao diálogo e a soluções consensuais com a vontade do povo, do qual emana o Poder Público.

Ora, a heterogeneidade de interesses detectados numa sociedade complexa demanda a necessidade de debates com os interessados acerca das medidas ou reformas que deverão ser adotadas, a fim de que as decisões tomadas sejam produtivas e eficientes, o que é alcançado de forma menos traumática quando se chega a um consenso. Consenso este diretamente ligado ao uso da linguagem adequada.

O presente artigo pretende então traçar um paralelo entre o que seriam esses jogos de linguagem, a textura aberta da linguagem e sua relação com o Direito na autocomposição administrativa.

Aborda-se primeiramente o problema semântico e as intoxicações da linguagem, as conclusões que Waismann e Wittgenstein tiraram desses problemas, da própria linguagem, criando o conceito de textura aberta da palavra.

Será descrito também como esse conceito aberto da palavra se relaciona com o Direito e por fim essas relações dentro da autocomposição administrativa, esta como sendo um 
equivalente judicial estimulado pelo atual arcabouço normativo pátrio, diante da sua inegável importância para uma solução mais célere das divergências e alcance da paz social.

\section{O PROBLEMA SEMÂNTICO (INTOXICAÇÕES LINGUÍSTICAS)}

No momento da aplicação da norma para resolução de conflitos algumas lacunas podem aparecer, as chamadas lacunas de conhecimento e as lacunas de reconhecimento.

Para nós não é importante, neste momento, a lacuna de conhecimento ${ }^{1}$ já que de um modo geral seria solucionada pelas presunções legais, como por exemplo, a boa-fé, o ônus probandi, etc. Estes permitem que o juiz seja capaz de determinar os fatos que possuem uma existência legal, mesmo quando ele não sabe da existência real de todos os fatos que poderiam ser relevantes para sua decisão.

Já as lacunas de reconhecimento, ou o problema das intoxicações linguísticas ${ }^{2}$, não são resolvidos assim facilmente. Isto porque, tal intoxicação decorre da indeterminação dos termos gerais empregados na norma. Mesmo se conhecemos todos os fatos de um caso particular, por exemplo, ainda assim não sabemos se ele deve ser inserido dentro da regra geral ou não. (LUZZATI, 1999)

Alchourron e Bulygin (1971) usam o seguinte exemplo: Nós podemos saber que Tício pagou a Simprônio uma quantia x pela casa. Porém, podemos não saber se essa quantia é suficiente para considerar a transferência como sendo onerosa ou não. Se a quantia paga é muito inferior ao valor de mercado da casa, talvez a transferência não seja uma venda, mas sim uma doação ou um presente disfarçado.

Percebe-se então que a intoxicação da linguagem (lacunas de reconhecimento) não pode ser superada definitivamente. Ela pode ser minimizada pelo emprego de termos mais técnicos, mais precisos, mais bem definidos, mas, em decorrência da textura aberta da linguagem, a indeterminação linguística é inextinguível.

\footnotetext{
${ }^{1}$ Quando não se sabe se um caso particular deve ser inserido dentro de uma norma geral por falta de conhecimento a respeito de fatos relevantes sobre o caso. Esse conhecimento pode ser suprido pela presunção legal, permitindo que a existência legal supra a existência real.

${ }^{2}$ Indeterminação semântica dos termos gerais empregados na norma, a lacuna aqui decorre da semântica da palavra.
}

Rev. de Teorias da Justiça, da Decisão e da Argumentação Jurídica | e-ISSN: 2525-9644| Maranhão | v. 3 | n. 2 | p. 37 - 52 | Jul/Dez. 2017. 


\subsection{A textura Aberta da Linguagem: Waismann e Wittgenstein}

E o que seria essa "textura aberta da linguagem?" Empregada de forma pioneira pelo filósofo Waismann, seria a constatação de que o significado das afirmações não se esgota com o fornecimento de um conjunto finito de experiências.

Defende o filósofo que, muito embora a verificação de um conjunto finito de experiências possa funcionar como "condição de assertibilidade" de uma afirmação, muitas vezes não é logicamente suficiente para esgotar o significado da mesma.

Para ele, conceitos empíricos apresentam uma estrutura aberta: por mais que possamos limitar esses conceitos em certas direções, contrastando esses termos com outros termos, sempre deixaremos de delimitá-los em outras direções, deixando lacunas na forma como seu uso deve ser efetivado. (WAISMANN, 1978)

A incompletude essencial das descrições empíricas seriam a causa da textura aberta da maioria dos conceitos empíricos.

Toda descrição se estende para um horizonte de possibilidades abertas: não importa a distância que eu percorra, eu sempre carregarei esse horizonte comigo...não existe completude no caso em que eu descrevo minha mão direita, ou o caráter de uma pessoa; eu nunca posso exaurir todos os detalhes ou prever todas as circunstâncias que me fariam modificar ou retirar a minha afirmação. (WAISMANN, 1978)

Segundo ele, nós nunca conseguimos criar um modelo ou definição capaz de antecipar todos os usos dos conceitos empíricos porque nós nunca podemos ter certeza de que incluímos na nossa definição tudo aquilo que deveria ter incluído. E isso decorreria da nossa própria natureza falível e da natureza do mundo, pois tanto nossos valores como o próprio mundo estariam em constante mudança.

Schauer (1998) preleciona que a textura aberta é essa característica indelével da linguagem, a consequência do confronto entre uma linguagem fixa e um mundo desconhecido em constante mudança.

Segundo Gordon Baker, o conceito de textura aberta da linguagem nasceu do conceito de hipótese (hypothesis) de Wittgenstein. Uma hipótese admite múltiplas verificações independentes, mas nenhuma delas, e nenhuma combinação delas, é conclusiva.

No máximo, uma hipótese se torna provável em função das evidências que servem para confirmá-la, mas nunca certa (BAKER, 1979) 
Então, assim como uma hipótese só pode se tornar mais ou menos provável em função das evidências, e jamais absolutamente certa, a afirmação empírica não pode ser verificada de forma conclusiva, em decorrência da textura aberta da linguagem.

Essa ideia de textura aberta da linguagem deriva das noções de "jogos de linguagem" e "semelhança de família", correspondentes a segunda fase de Wittgenstein período de composição das obras Philosophical Remarks e Philosophical Grammar.

Wittgenstein, filósofo austríaco, foi o maior expoente da filosofia da linguagem. Sua obra é dívida nitidamente em duas fases. Fases estas antagônicas entre si.

A sua primeira fase, correspondente a sua única obra publicada em vida, o Tractatus Logico-Philosophicus (1994). Nela ele traz a teoria pictórica do significado, as palavras como pintura do mundo. De acordo com essa teoria, haveria um modelo único, específico que toda linguagem deveria respeitar para ser dotada de sentido.

Para esse modelo, a forma lógica da proposição deve corresponder à estrutura ontológica do real. Diz o filósofo, nesta fase, que só é possível falar significativamente quando a linguagem estiver circunscrita ao mundo, fora disso, a linguagem não significa. Ou seja, apenas as proposições que conseguem afigurar o estado de coisas conseguem ter sentido. Tratase de um isomorfismo. Os termos que compõem as proposições possuem uma proposição absoluta, um significado fixo, ou rígido.

Os termos usados na proposição não apenas correspondem aos objetos do real, mas substituem os objetos na linguagem. Assim, sempre que o mesmo termo for usado, ele estará substituindo o mesmo objeto real.

Já em sua segunda fase, nas Investigações Filosóficas (1996), Wittgenstein rompe com a teoria pictórica do significado e passa a tratar da linguagem natural, levando em conta toda sua riqueza e complexidade. Aqui, o significado não é mais uma coisa do outro lado da palavra, mas sim alcançado pelas regras que utilizamos para inserir a palavra em nossa vida.

Não há que se perguntar pelo significado da palavra, mas sim pelo seu uso. Nessa segunda fase, não há propriamente uma linguagem, mas linguagens de acordo com as formas de vida. (WITTGENSTEIN, 1996)

Ele abandona a ideia de um único modelo capaz de dar sentido à linguagem e incorpora as noções de jogos de linguagem e semelhança de família na sua filosofia para mostrar como, apesar da heterogeneidade da linguagem, ela ainda assim funciona. Trata-se de uma visão não essencialista da linguagem. (WITTGENSTEIN, 1996) 
Para esse segundo Wittgenstein, a linguagem não é sempre uma representação dos fatos do real, mas sim uma atividade, capaz de exercer uma pletora de funções divergentes. (WITTGENSTEIN, 1996)

Os termos que compõem as proposições deixam de ser substituições dos objetos do real no âmbito da linguagem e passam a ser considerados como ferramentas, que podem ser usadas de maneiras diferentes, dependendo da função que devem realizar.

E é em função das ideias acimas narradas que Wittgenstein resolve explicar a linguagem recorrendo ao conceito "jogo". Uma vez que, assim como ocorre nos jogos os fenômenos conhecidos como "linguagem" não possuem uma característica comum que percorre e pode ser identificada em todas as suas instâncias. Aqui você não vê na verdade, algo comum a todos, mas verá semelhanças, parentescos e até toda uma série deles. (WITTGENSTEIN, 1996)

O uso da palavra jogo quer trazer o conceito de contornos imprecisos. E é justamente esse contorno impreciso que pode ter sua extensão de aplicação ampliada no tempo que é compatível com a noção de textura aberta da linguagem.

Afinal, segundo Waismann, a aplicação ou uso dos termos empíricos não é estática, podendo sempre surgir casos que requeiram a reformulação da definição do conceito empírico.

\subsection{A Textura Aberta da Linguagem e o Direito}

Robert Alexy, um dos pais da teoria da argumentação jurídica, fala em diversos trabalhos sobre o fenômeno da textura aberta e o problema da vaguidade na linguagem jurídica.

Mas o responsável pela transposição dessa discussão para a teoria do direito foi H. L. A. Hart. Segundo ele, uma das principais razões para a dificuldade na aplicação das regras jurídicas é o fato de elas possuírem uma textura aberta.

As regras são constituídas por termos gerais dotados de textura aberta. Isso significa que não sabemos todas as ocasiões em que uma regra deve ser aplicada ou não. Toda regra é potencialmente vaga.

A decisão acerca da aplicação da regra em um caso concreto muitas vezes recai na questão sobre o significado ou abrangência de um termo geral classificatório encontrado na 
regra. Essa dificuldade encontrada é decorrente da natureza da linguagem, que é potencialmente vaga.

Alchourron e Bulygin (1971) fazem interessante consideração: O fato de um sistema normativo ser completo (normativamente), no sentido de que ele resolve todos os casos possíveis, tanto genéricos quanto individuais, não exclui a possibilidade de que um caso individual cuja classificação é duvidosa possa surgir.

Hart (1968) expõe que a interpretação do juiz sobra a aplicação da regra só é necessária quando existe dúvida ou divergência a respeito da aplicação dos termos gerais. Segundo ele, as interpretações criativas só devem ocorrer quando as nossas convenções linguísticas não conseguem determinar, de forma segura, como deve ser efetivado os termos gerais. Esses termos gerais seriam quando as palavras não extrapolam seu uso ordinário.

Portanto, quando um juiz se depara com um caso anômalo, a sua atividade não consiste mais em mera dedução. Ele não pode simplesmente aplicar o direito, mas sim interpretá-lo.

O papel da interpretação é justamente eliminar essa indeterminação da regra para o caso em questão. Portanto, a necessidade de interpretação está vinculada à ocorrência dos casos difíceis (situados na penumbra dos termos gerais).

Assim, quando o juiz interpreta a regra, escolhendo e argumentando a favor de um dos significados possíveis que podem ser atribuídos a ela, ele está exercendo o seu poder discricionário.

Ressalte-se que essa discricionariedade trazida por Hart não se confunde com a arbitrariedade. Para Hart (1968), o poder discricionário que é deixado para o juiz em decorrência da linguagem, em certas ocasiões é tão amplo, que chega a ser uma escolha.

Mas, isto não quer dizer que esta escolha seja arbitrária ou irracional. Aqui entram teóricos da argumentação jurídica, que vão indicar de forma minuciosa os problemas que podem decorrer dessa discricionariedade e as possíveis formas de se trabalhar racionalmente dentro dessa região de penumbra desses casos difíceis do direito.

Hart questiona a capacidade de operar das regras de uma maneira a priori, levantando os problemas que a linguagem usada para constituí-las pode apresentar e de que maneira isso pode comprometer o funcionamento do direito.

A resposta que ele encontra é que o direito funciona porque toda regra tem um núcleo de certeza onde a maioria dos casos são encontrados e onde é possível saber se ela dever ser aplicada ou não. 
Como na maioria dos casos, a linguagem da regra é facilmente compreendida por todos, sem a necessidade de maiores explicações, então o direito é capaz de cumprir sua função precípua: guiar comportamentos futuros. Ou seja, é em função da existência de um núcleo de certeza nas regras que os critérios para existência do direito são preenchidos. (HART, 1968)

\subsection{A Vaguidade e o Direito}

Pelo narrado acima se depreende que a textura aberta da linguagem significa a sua potencial vaguidade. Significando que a mais precisa das regras pode se tornar imprecisa, existindo diferença, porém entre uma regra que sempre foi vaga e uma que se tornou vaga.

A textura aberta da linguagem jurídica, ou a sua potencial vaguidade, é inexorável. Sempre pode surgir um caso não antecipado que se encontra na região de penumbra do significado da regra. Porém, permanece a questão sobre a possibilidade de se eliminar a vaguidade de um determinado ordenamento jurídico em um determinado momento.

O ponto é que nem mesmo a vaguidade mais atual pode ser erradicada totalmente de um sistema jurídico. É possível criar leis precisas, mas um ordenamento jurídico totalmente livre de vaguidade é impossível.

A precisão da regra, contudo, sempre configura um obstáculo para a concretização de seu propósito. Essa precisão contém algumas virtudes, como a segurança, a certeza e estabilidade e segundo Endicott (2001) ela ainda traz a redução de dúvidas e discordâncias. As regras precisas no direito fazem com que as pessoas saibam exatamente o que é esperado delas e evita disputas.

Tomemos como exemplo o Código de Trânsito Brasileiro. Este contém regras extremamente precisas. A regra que coloca o limite de 6 decigramas de álcool por litro de sangue como critério que configura a embriaguez é uma delas.

O propósito de regras como essa é prevenir riscos, mas sem interferir indevidamente na liberdade das pessoas. Entretanto, se as pessoas apresentam diferentes níveis de tolerância em relação ao álcool, se é o caso que o organismo de algumas pessoas suporta uma quantidade de álcool acima do estabelecido em lei, sem que isso afete a sua capacidade de dirigir, então a regra é arbitrária. 
Então se conclui que toda regra precisa é arbitrária em função de sua precisão, porém o que ocorre é que na maioria das vezes essa precisão está justificada porque evita outras arbitrariedades.

Para Endicott (2001) a busca pela precisão absoluta estaria fadada ao fracasso em qualquer sistema jurídico atual em função das técnicas de interpretação, que mesmo quando não incorporadas no sistema jurídico de forma explícita, se encontram sedimentadas na pratica jurídica.

As técnicas de interpretação do direito podem fazer com que o efeito de uma proposição linguística seja vago. As regras precisas produzidas pelos legisladores só irão produzir normas precisas se os juízes tiverem boas razões para conferir a elas um efeito preciso.

As técnicas interpretativas unidas ao caráter sistêmico do direito e aos princípios gerais do direito possibilitam que uma formulação linguística precisa por parte dos legisladores se torne vaga.

\section{Assim preleciona Raz:}

O direito é expresso em palavras e, na maioria das vezes, é criado pelo uso de palavras. Mas é errado concluir que, portanto, existe uma relação de replicação direta entre a vaguidade das palavras e expressões e a vaguidade do direito [...] O direito é sistêmico e cada uma de suas regras deriva seu significado não somente do proferimento que deu origem a ela, mas de outras partes do direito. Como resultado, a vaguidade das palavras utilizadas pode não ser transferida para o direito e outros fatores podem tornar o direito vago mesmo quando as palavras usadas na sua composição não o eram. (RAZ, 1978)

Uma precisão absoluta das regras legais não é totalmente desejável, já que traz consigo certo grau de arbitrariedade. Portanto, afirma Endicott (2001) que certa dose de flexibilidade é uma boa medida para qualquer sistema jurídico que se pretenda justo e equânime. De acordo com ele o Direito está analiticamente entrelaçado com a vaguidade.

Logo, é da natureza do direito tratar de coisas cuja natureza não pode ser apreendida por meio de linguagem precisa. Desta forma, o direito é necessariamente vago.

E, se as regras jurídicas são constituídas por termos gerais dotados de textura aberta, e se, portanto, as regras e, em última instância, o direito são necessariamente vagos, então está aberto o caminho para a teoria da argumentação jurídica.

\section{A LINGUAGEM NA AUTOCOMPOSIÇÃO ADMINISTRATIVA}


Prima facie, faz-se necessário tecer algumas noções do instituto da autocomposição administrativa.

Em breve digressão, o amplo acesso ao Poder Judiciário para a solução de pretensões resistidas acabou por lhe sobrecarregar, gerando impacto negativo na efetividade de sua atuação e assim, surgiu a necessidade de novas formas de composição de conflitos.

Inegável que esse fenômeno decorreu do reconhecimento de que a prestação jurisdicional se tornou demasiadamente custosa e com eficácia tardia.

Nesse contexto, a autocomposição apareceu como a utilização de mecanismos negociação, mediação ou conciliação - com o objetivo de evitar a judicialização da demanda. Portanto, necessário se faz demonstrar a distinção entre os mencionados mecanismos:

Na negociação os próprios interessados alcançam a solução das divergências/conflitos por meio de um acordo direto, sem a intervenção de um terceiro.

Já a mediação exige a participação de um terceiro não interessado que figura como facilitador, incentivando o diálogo para que os interessados realizem o acordo possível.

No tocante à conciliação, esta consiste na interferência de um terceiro que conduzirá o processo de pacificação do conflito, apresentando em regra propostas para a composição do acordo. Ressalte-se que a conciliação pode ser extrajudicial ou judicial, esta se desenvolve durante o andamento de um processo e pressupõe a homologação do juiz, ao passo que aquela pode ou não prescindir de homologação judicial.

Tradicionalmente a composição dos conflitos envolvendo bens e interesses públicos se dava diante do Poder Judiciário, onde o Estado- Juiz se posicionava de modo a substituir a vontade dos titulares de interesses divergentes.

Contudo, a atual conjuntura demanda uma atuação mais incisiva por parte da Administração Pública, haja vista que a legalidade não deve mais ser vista como simples subsunção do fato à norma, mas sim como uma via de mão dupla na busca do consenso entre gestores e administrados por meio da concepção dialógica, ou seja, em uma vertente democrática.

Tal entendimento não resulta, porém, em uma ofensa ao postulado da indisponibilidade do interesse público já que tais transações não significam puro arbítrio, pois devem estar em conformidade com os demais princípios que regem a Administração Pública.

Assim, diante da referida autorização legal para que a Administração Pública, como regra geral, possa realizar Conciliações e Mediações Judiciais ou Extrajudiciais, mostra-se 
superada qualquer alegação de ofensa ao princípio da legalidade ao se aplicar os meios alternativos de soluções de controvérsias no âmbito da Administração Pública, bem como, deve-se eliminar a contraposição por parte da doutrina, entre o princípio da supremacia do interesse público e da autonomia privada.

Ademais, imperioso destacar que a Lei n. ${ }^{\circ} 13.140$, de 26 de junho de 2015, regula a autocomposição de conflitos no âmbito da Administração Pública, a qual também respaldará as Conciliações e Mediações autocompositivas, portanto, garantindo autorização legislativa para soluções alternativas consensuais de questões envolvendo o Poder Público.

Outrossim, o atual Código de Processo Civil, traz dentre as suas inovações, relevantes dispositivos referentes aos métodos consensuais de solução de conflito, tantos nas lides entre particulares como naquelas envolvendo o Poder Público. Neste contexto podemos mencionar, a título de exemplo, o artigo $6^{\circ}$ desse regramento, de forma genérica, estimula a conciliação; já o artigo 174 estabelece a criação de câmaras de mediação e conciliação, cujas atribuições englobam a avaliação dos pedidos de resolução de conflitos, por meio de conciliação, no âmbito da administração pública.

Nota-se também, à título de informação, a presença de um movimento nacional de adoção do instituto da autocomposição dos conflitos perante os vários Entes fiscalizadores estaduais, em especial, o denominado Termo de Ajustamento de Gestão, através do qual o Tribunal de Contas poderá negociar com seus jurisdicionados práticas de gestão que tenham por fim prevenir ou corrigir irregularidades.

Surgindo então, um novo paradigma de controle em substituição ao tradicional controle-sanção, que vai perdendo sua força na sociedade hodierna, qual seja o controle consensual.

Neste panorama, o Termo de Ajustamento de Gestão é norteado pelos princípios da boa-fé, consensualidade e voluntariedade, ou seja, sem afetar a discricionariedade do gestor. E, de uma forma geral, o instrumento deve nomear as autoridades signatárias, obrigações pactuadas e prazo para sua implementação, bem como eventuais penalidades em caso de descumprimento.

Porém não existe uma uniformidade em relação às situações comunicacionais que deverão possibilitar o início desse diálogo entre o Tribunal de Contas e os jurisdicionados, havendo, então, consoante Iocken (2015), a necessidade de intercâmbio entre as novas perspectivas do Código de Processo Civil e uma reformulação processual no âmbito do controle 
externo, face à necessidade de adoção de um arcabouço processual e jurídico equânime, capaz de corporificar as premissas teóricas direcionadas à atividade de jurisdição de contas.

Assim, inegável que o uso de métodos autocompositivos também por parte da Administração Pública, além de estar respaldado legalmente, afigura-se em conformidade com a moderna tendência de encerramento de divergências, seja nas divergências com particulares ou mesmo entre seus órgãos.

Retomando o instituto da mediação, esta possui alguns princípios típicos, dentre os quais é possível destacar os seguintes: a voluntariedade, que corresponde ao reconhecimento da livre participação dos interessados, num eventual acordo resultante da mediação, ressaltando-se que esta participação livre significa a inexistência de coação ou coerção entre os participantes; outro princípio é o do consentimento informado, que se refere ao direito de esclarecimento dos interessados sobre a mediação, seus alcances, seus efeitos e restrições nas relações hodiernas.

Destaca-se ainda, o princípio da autodeterminação das partes, significando a capacidade de responsabilização dos envolvidos sobre o alcance da celebração do acordo pretendido. O princípio da imparcialidade, por sua vez, diz respeito ao direito que as partes possuem de ter um condutor neutro durante o decorrer de todo o procedimento autocompositivo, garantindo assim a sua máxima efetividade. Por fim, registre-se o importante princípio da confidencialidade, ou seja, o sigilo das informações trazidas à baila durante as tratativas da mediação, fazendo com que a partes se sintam protegidas pelo manto da discrição.

Contudo, na resolução de conflitos da administração pública a aplicação desses princípios demanda uma ponderação com os demais princípios administrativos. Nesse contexto, o princípio da confidencialidade da mediação mostra-se conflitante com os princípios da publicidade e da impessoalidade, devido à necessidade de a administração evidenciar todos os seus atos, ressalvados os sigilos legais.

Dito isso, e somando-se ao conceito da textura aberta da palavra e suas intoxicações temos que a autocomposição de conflitos para ser exitosa tem que fazer uso desse jogo de linguagem, desse conceito aberto da palavra.

Isto porque, em cada tentativa de solução extrajudicial de conflitos a linguagem tem que alcançar a máxima efetividade naquela situação, naquele jogo. Ou seja, a mensagem do emissor, naquela tratativa, deve ser adequadamente compreendida pelo receptor de maneira que seja alcançado o consenso necessário para a pacificação social. 
E ressaltando que cada composição de conflitos tem suas especificidades, o que pode fazer com que o sentido de uma palavra em uma composição já não se adeque a outra composição, deixando bem clara a necessidade desse jogo de linguagem, no qual a palavra vai adquirir o significado através de seu uso, consoante sua inexauribilidade semântica.

O agir comunicativo indelével na autocomposição administrativa, deve satisfazer condições de entendimento e de cooperação, os participantes devem comportar-se de maneira a cooperar e colocar seus planos em sintonia uns com os outros, na busca sincera do entendimento. (CARDOSO, 2013)

Nesse uso da linguagem o falante quer comunicar ao ouvinte determinado fato ou intenção, de tal modo que este se convença de tal fato ou que leve a sério que o falante realizará aquilo que está manifestando. E não simplesmente emitir sua opinião ou intenção ao ouvinte: se pretende aqui, na autocomposição que o ouvinte chegue a mesma conclusão que ele. Ou seja, que se chegue à resolução daquele conflito.

Satisfeitas as condições de entendimento e cooperação, adquire máxima relevância a busca do bom senso na autocomposição dos conflitos. Os mediadores deverão tornar claro aos envolvidos que se o jogo de palavras for utilizado com verdade, sinceridade e em coordenação, podem atingir melhores resultados do que o agir estrategicamente, ou atribuírem a terceiro não interessado e imparcial (julgador) a solução dos conflitos. (CARDOSO, 2013)

O consenso na autocomposição administrativa de conflitos, através dessa adaptação da linguagem, desse jogo, trará, necessariamente, resultado mais justo e célere para a satisfação dos interesses em discussão.

\section{CONCLUSÃO}

Em decorrência do aumento do acesso ao Poder Judiciário e, por conseguinte da morosidade da heterecomposição dos conflitos, surgiu a necessidade da criação da cultura de conciliação. Ou seja, novas formas para a solução dessas lides sem a intervenção do Judiciário, já sobrecarregado em razão do alto índice de litigiosidade da sociedade brasileira, de forma que não têm conseguido garantir uma resolução em tempo hábil das demandas postas à sua disposição.

A autocomposição, neste panorama, busca então estabelecer o consenso entre as partes litigantes, para que se chegue a uma solução satisfatória à todos os envolvidos, abrindo 
importante capítulo na solução dos litígios, conferindo maior celeridade e eficiência na resolução de controvérsias.

Em sendo assim, e tendo em visto que o Poder Público, de um modo geral, é um dos litigantes que mais possui demandas que aguardam soluções no Poder Judiciário, natural que não exista óbice à utilização por aquele, dessa solução alternativa de conflito.

Inclusive, conforme amplamente demonstrado no decorrer do texto, o uso da autocomposição administrativa não representa desrespeito ao princípio da indisponibilidade do interesse público, tendo em vista que a atual conjuntura requer uma atuação mais proativa e dialógica por parte do Estado.

A linguagem nesse processo é peça fundamental para o êxito, pois o discurso utilizado interferirá diretamente no convencimento das partes para a elaboração da solução do conflito posto.

Acontece que, conforme explanado, a linguagem é permeada de intoxicações e problemas, além das dificuldades ocasionadas pela amplitude da semântica linguística. Pois, do mesmo modo que essa amplitude flexibiliza o teor normativo, pode tornar inesgotável seu viés interpretativo.

Assim, para o alcance do bem comum é necessário que se tenha em mente a textura aberta das palavras, ou seja, que o sentido dela seja trazido pelo seu uso, definido pelo jogo que ali se apresenta. Haja vista a necessidade de que a mensagem seja transmitida e compreendida de maneira adequada à pacificação da divergência. Sendo primordial para essa máxima compreensão o conhecimento e aplicação correta do jogo da linguagem trazido por Wittgenstein e explicitado no presente artigo.

Por todo o exposto, tem-se que uma Administração Pública proba e eficiente é aquela que realiza seu poder-dever de garantir as demandas da sociedade de maneira célere e eficaz, na busca do bem comum, fazendo uso de todo o aparato linguístico e jurídico disponível para tanto.

E, inegável que, para que se extraia a máxima efetividade do uso dos meios alternativos de solução de litígios, a linguagem deve ser aplicada de maneira otimizada, lhe sendo tirada todos os vícios que possam embaralhar a relação emissor/receptor, vez que seria o meio imprescindível para o consenso.

\section{REFERÊNCIAS}


AlCHOURRÓN, C., BUlYGIN, E. Normative Systems. Nova York: SpringerVerlag/Viena, 1971.

BRASIL. Lei $\mathbf{n}^{\mathbf{0}} \mathbf{1 3 . 1 4 0}$, de 26 de junho de 2015. Disponível em: <http://www.planalto.gov.br/CCIVIL_03/_Ato2015-2018/2015/Lei/L13140.htm>. Acesso em: 15 jul. 2016.

CARDOSO, Henrique Ribeiro. Mediação de Conflitos? A Atualidade da teoria do agir comunicativo. In: SILVA, L.A.M.G.. (Org.). Mediação de Conflitos. A Atualidade da teoria do agir comunicativo. 1. ed.: Atlas, 2013.

CAVALCANTE, Márcio André Lopes. Comentários a Lei 13.140/2015 (Lei da Mediação). Disponível em: < http://www.dizerodireito.com.br/2015/06/comentarios-lei-131402015-leida.html>. Acesso em: 17 ago. 2016.

DONIAK, Alessandra Alves. Conciliação Judicial no Âmbito da Administração Pública Federal. Disponível em: <http://www.conteudojuridico.com.br/artigo,conciliacao-judicial- noambito-da-administracao-publica-federal,52435.html>. Acesso em: 13 jul. 2016.

ENDICOTT, T. Law is Necessarily Vague. Legal Theory, no 7, 2001.

FERRAZ, Júnior. Tércio Sampaio. Direito Retórica e comunicação: subsídios para uma pragmática do discurso jurídico. Saraiva. 2 ed. São Paulo: 1997.

GAZDA, Emmerson. Administração Pública em juízo: poder-dever de transigir. Disponível em:<http://www.revistadoutrina.trf4.gov.br/index.htm?http://www.revistadoutrina.trf4.gov.br/ ar tig os/edicao010/emmerson_gazda.htm>. Acesso em: 17 jul. 2016.

HART, H. L. A. Kelsen Visited. In: UCLA Law Review. no 10, p. 709-728, 1962-1963.

Kelsen's Doctrine of the Unity of Law. In: HOWARD, E. Et al. (Ed.) Ethic and social justice. no 4. Albany: State University of New York Press, 1968.

IOCKEN, Sabrina N. Políticas Públicas: O controle do Tribunal de Contas. 1ed. Florianópolis: Conceito Editorial, 2013. v. 1.142p.

IOCKEN, Sabrina N; OLIVO, L. C. C..A Plenitude Jurisdicional do Controle: Um Novo Desafio para o Estado Democrático de Direito. In: Bleine Queiroz Caúla; Geraldo Clésio Maia Arruda; Nathalie de Paula Carvalho; Valter Moura do Carmo. (Org). Diálogo Ambiental, Constitucional e Internacional. 1. ed. Rio de Janeiro: Lumen Juris, 2015, v. 3, p. 173-189.

LUZZATI, C. Indeterminação. In: ARNAUD, A. Dicionário Enciclopédico de Teoria e Sociologia do Direito. Rio de Janeiro: Editora Renovar, 1999.

RAZ, J. (Ed.) Practical Reasoning. Oxford: Oxford University Press, 1978. 
WAISMANN, F. Verifiability. In: FLEW, A. G. N. (ed.). Logic and Language (First Series). Oxford: Basil Blackwell, p.117-144, 1978.

The Principles of Linguistic Philosophy. Londres: The Macmillan Press Ltda., 1971.

WITTGENSTEIN, L. Tractatus Logico-Philosophicus. São Paulo: Ed. Universidade de São Paulo, 1994.

Investigações Filosóficas. Coleção Os Pensadores. São Paulo: Nova cultural, 1996. 